\title{
Bilateral Complete Visual Loss in Chiari I Malformation
}

Larissa M Pastore ${ }^{1^{*}}$, Domenic J Pastore ${ }^{2}$ and Samantha Pastore ${ }^{3}$

${ }^{1}$ Department of Biology, Villanova University, USA

${ }^{2}$ Opthalmologist, Mainland Eye Ophthalmology, USA

${ }^{3}$ Department of Biochemistry, Villanova University, USA

*Corresponding author: Larissa M Pastore, Department of Biology, Villanova University, USA, E-mail: 1pastore@villanova.edu

Received Date: Sep 10, 2018; Accepted Date: Oct 01, 2018; Published Date: Oct 10, 2018

Copyright: (c) 2018 Pastore LM, et al. This is an open-access article distributed under the terms of the Creative Commons Attribution License, which permits unrestricted use, distribution, and reproduction in any medium, provided the original author and source are credited.

\begin{abstract}
Acute bilateral complete visual loss is often a very challenging complaint for physicians and practitioners. The presentation of loss of sight in both eyes simultaneously, particularly in younger patients, in the absence of ophthalmic exam findings is so improbable that a diagnosis of factitious disorder or malingering is often assigned. This case demonstrates that Chiari I brain malformations, an incidental but not uncommon radiologic finding, may often be the etiology of such cases of bilateral complete loss of vision. Herniation of brain tissue into the spinal canal is the hallmark of Chiari malformations with subsequent compression of the posterior cerebral artery resulting in bilateral occipital lobe ischemia. Careful interpretations of brain MRI findings are critical in making this diagnosis. We report a 29-year old healthy female who presented to the ophthalmologist's office with a complaint of transient bilateral vision loss. This case study demonstrates that incidental Chiari I malformation findings may also be pertinent to symptoms of bilateral vision loss. In addition, a patient complaint of bilateral vision loss should be followed up with an MRI and consult with a radiologist and neurologist with Chiari I malformation being included in the differential diagnoses. To the best of our knowledge, this will be the first reported case of bilateral visual loss due to a Chiari type I malformation.
\end{abstract}

Keywords: Chiari I malformation; Bilateral acute visual loss; Case study

Abbreviations MRI: Magnetic Resonance Imaging, CBC: Complete Blood Count, EEG: Electroencephalogram, BUN: Blood Urea Nitrogen

\section{Introduction}

Although acute bilateral visual loss is a rare presenting symptom, there are nonetheless a multitude of diagnostic possibilities. In the past, many case reports depict bilateral cortical blindness, either transient or permanent loss of vision secondary to ischemic and thrombotic causes [1-3]. Severe hypoxia and hypotension have also been identified [4].

We identified a case of Chiari I malformation as the underlying cause of acute bilateral visual loss. In addition, we noted that classic MRI findings which are usually characterized as incidental were in fact beneficial in identifying the cause of the visual loss. As far as we are aware, this is the first reported incident of Chiari I malformation as the underlying factor in acute bilateral loss of vision.

\section{Case Presentation}

\section{History}

A 29 year old Hispanic female from Puerto Rico presented with a chief complaint of acute bilateral visual loss. She describes two to three episodes per week of complete visual loss where she sees absolutely nothing at all. This is associated with episodic unresponsiveness, diaphoresis, irregular breathing and extensor rigidity of the extremities which resembles a seizure disorder. This has been going on for 6 years.

\section{Diagnostic data}

Vision was correctable to 20/20 in each eye. There was no afferent pupillary defect. There was no ocular motility deficit. Anterior segment exam was clear and quiet. Eye pressures were 12 in each eye. Dilated Fundus Exam was unremarkable showing a normal optic nerve in each eye with no optic disc edema. Retinal vasculature and maculae were also normal.

\section{Follow up}

The patient was then discharged from the ophthalmologist's office with a diagnosis of episodic inflammatory optic neuritis. The diagnosis in Puerto Rico was neuromyelitis optica.

The following week, the patient returned to work and at the work place suffered another episode of bilateral complete visual loss associated with unresponsiveness, rigidity, diaphoresis and apnea. Threatening hand motions towards the patient's eyes by a nurse on the scene confirmed no flinch or blink response confirming complete bilateral visual deficit. The patient was transferred to the emergency room via paramedics and admitted to the hospital for work up with a provisional diagnosis of seizure disorder.

\section{Hospital work up}

Upon arrival, the patient was responsive. Vital signs were normal. No post-ictal state was observed during the transfer to the hospital or in the emergency department. $\mathrm{CBC}$ and platelet count was normal. Electrolytes, BUN and creatinine were normal. B12 was normal, but Folate level was decreased. The only other significant lab values were a slightly elevated serum glucose level and trace ketones found in the urine. An EEG showed no evidence of seizure disorder. An MRI scan 
of the brain showed a Chiari I malformation which was termed an incidental finding by the radiologist and likely unrelated to her symptoms. A diagnosis of malingering or factitious disorder was given and the patient was discharged to seek a psychiatry consultation.

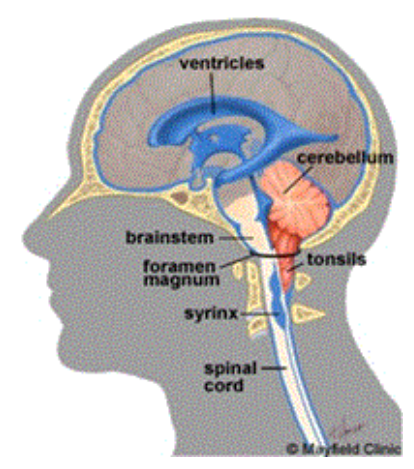

Figure 1: Schematic of Chiari I malformation showing herniation of the cerebellar tonsils through the foramen magnum (Adapted from the Mayfield Clinic).

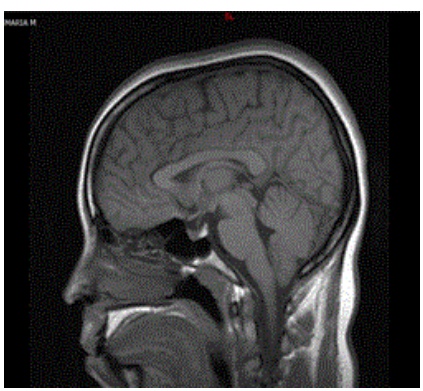

Figure 2: MRI sagittal view of patient showing approximately $1.5 \mathrm{~cm}$ herniation of the cerebellar tonsils through the foramen magnum.

\section{Discussion}

Acute bilateral complete visual loss is rarely seen in the physician's office or emergency department [1]. Upon such a presentation, an unremarkable eye exam is the usual clinical finding [1]. When a patient describes a history of acute bilateral complete visual loss, a systematic approach to the causative factors are mandatory [1]. The typical causes are usually conditions of cerebral vascular insufficiency and include stroke, hypoxia, hypotension, thrombosis, but may also include less likely entities such as systemic lupus, meningitis, and chemotherapy [2-8].

Despite the myriad of possible diagnoses of acute visual loss, it is often tempting to declare bilateral loss of vision as malingering or factitious disorder when strong clinical findings are absent [9]. This can be dangerous and delay a more severe diagnosis [10].

In this case, acute bilateral complete visual loss was a result of a Chiari I malformation (Figures 1 and 2). Chiari I malformation is a type of anatomical disorder which features herniation of posterior brain tissue into the spinal canal, usually involving the lower portion of the cerebellum [11]. Chiari I malformation is not an unusual finding on MRI scan. As much as $0.8-1 \%$ of all patients undergoing MRI scan of the brain have a Chiari I malformation [12]. The condition is usually asymptomatic and the MRI findings are often declared incidental, however Chiari I malformations can occasionally be associated with 'cerebellar fits', a symptom that is characterized by drop attacks, extensor posturing of the extremities, and irregular respiration [13]. Neuroophthalmic symptoms may also be seen and include headaches, diplopia, strabismus, nystagmus, and blurred vision [14]. Nonetheless, complete bilateral loss of vision due to a Chiari I malformation has not been officially reported.

\section{Conclusions}

Chiari I malformations are mostly asymptomatic and, in the past, have not been formally associated with acute bilateral visual loss. A possible mechanism could involve compression of the posterior cerebral arteries against the tentorium, which in turn constricts blood flow to the occipital lobes leading to bilateral loss of vision $[15,16]$. In the future, an underlying Chiari I malformation should be heavily considered in all cases of acute bilateral loss of vision. MRI of the brain should be obtained and should be carefully inspected for a Chiari malformation.

\section{Acknowledgement}

We would like to thank our participant who took part in this case study and gave her consent for publication. This case report has been presented as a poster session at the 2017 Undergraduate Research Symposium at Villanova University. A poster abstract has been published.

\section{Competing Interests}

The authors declare that there is no conflict of interest regarding the publication of this paper.

\section{Funding}

None.

\section{References}

1. Hoover BW, Stack LB (1996) Acute Bilateral Blindness. Acad Emerg Med 3: 1056-1059.

2. Stiller RJ, Leone-Tomaschoff S, Cuteri J, Beck L (1990) Postpartum pulmonary embolus as an unusual cause of cortical blindness. Am J Obstet Gynecol 162: 696-697.

3. Coutteel C, Leys A, Fossion E, Missotten L (1991) Bilateral blindness in cavernous sinus thrombosis. Int Ophthalmol 15: 163-171.

4. de Souza A, de Souza R J, Pai Kakode VR (2017) Delayed-onset Reversible Cortical Blindness after Resuscitation from Cardiac Arrest. J Neurosci Rural Pract 8: S133-S135.

5. Tanrikulu CS, Hocagil H, Kaya U, Hocagil AC (2016) Acute bilateral vision loss in emergency department: A case report. Turk J Emerg Med 16: 38-40.

6. Cohen DB, Glasgow BJ (1993) Bilateral optic nerve cryptococcosis in sudden blindness in patients with acquired immune deficiency syndrome. Ophthalmology 100: 1689-1694.

7. Heran F, Defer G, Brugieres P, Brenot F, Gaston A, et al. (1990) Cortical blindness during chemotherapy: clinical, CT, and MR correlations. J Comput Assist Tomogr 14: 262-266.

8. Nasser SM, Fields P, Calver D, Bresnihan B, Gibson T (1993) Irreversible blindness in systemic lupus erythematosis. Br J Rheumatol 32: 935-936. 
Citation: Pastore LM, Pastore DJ, Pastore S (2018) Bilateral Complete Visual Loss in Chiari I Malformation. Med Rep Case Stud 3: 166. doi:

Page 3 of 3

9. Villegas RB, Ilsen PF (2007) Functional vision loss: a diagnosis of exclusion. Optometry 78: 523-533.

10. Drymalski WG (1980) Cortical blindness: the changing incidence and shifting etiology. Postgrad Med 67: 149-152, 155-156.

11. Speer MC, Enterline DS, Mehltretter L, Hammock P, Joseph J, et al. (2003) Chiari Type I Malformation with or without Syringomyelia: Prevalence and Genetics. J Genet Couns 12: 297-311.

12. Pandey A, Robinson S, Cohen AR (2001) Cerebellar fits in children with Chiari I malformation. Neurosurg Focus 11: E4.

13. Taylor FR, Larkins MV (2002) Headache and chiari I malformation: Clinical presentation, diagnosis, and controversies in management. Curr Pain Headache Rep 6: 331-337.
14. Shaikh AG, Ghasia FF (2015) Neuro-ophthalmology of type 1 Chiari malformation. Expert Rev Ophthalmol 10: 351-357.

15. Hoyt WF (1960) Vascular lesions of the visual cortex with brain herniation through the tentorial incisura: Neuro-ophthalmologic considerations. Arch Ophthalmol 64: 44-57.

16. Wong CW, Chen TY, Liao JJ, You DL (1993) Serial regional blood flow and visual evoked responses in transient cortical blindness. Acta Neurochir (Wien) 120: 187-189. 